俩 



\title{
Grundzüge der
}

Volkswirtschaftslehre

\author{
Von \\ Universitätsprofessor \\ Dr. Heinz-Dieter Hardes \\ und \\ Dipl.-Volkswirt Frieder Schmitz
}

7., neubearbeitete Auflage

R.Oldenbourg Verlag München Wien 


\title{
Die Deutsche Bibliothek - CIP-Einheitsaufnahme
}

\section{Hardes, Heinz-Dieter:}

Grundzüge der Volkswirtschaftslehre / von Heinz-Dieter Hardes und Frieder Schmitz. - 7., neubearb. Aufl. - München ; Wien :

Oldenbourg, 2000

ISBN 3-486-25347-6

\author{
C 2000 Oldenbourg Wissenschaftsverlag GmbH \\ Rosenheimer Straße 145, D-81671 München \\ Telefon: (089) 45051-0, Internet: http://www.oldenbourg.de
}

Das Werk einschließlich aller Abbildungen ist urheberrechtlich geschützt. Jede Verwertung außerhalb der Grenzen des Urheberrechtsgesetzes ist ohne Zustimmung des Verlages unzulässig und strafbar. Das gilt insbesondere für Vervielfăltigungen, Übersetzungen, Mikroverfilmungen und die Einspeicherung und Bearbeitung in elektronischen Systemen.

Gedruckt auf săure- und chlorfreiem Papier

Druck und Bindung: R. Oldenbourg Graphische Betriebe $\mathrm{GmbH}$, München 